\title{
Intracerebroventricular Route of Administration
}

National Cancer Institute

\section{Source}

National Cancer Institute. Intracerebroventricular Route of Administration. NCI

Thesaurus. Code C149600.

Administration of a medicinal product into the cerebral ventricles (cerebral ventricular system) of the brain. 